\title{
Catalytic Hydrogenation of D-Xylose Over Ru Decorated Carbon Foam Catalyst in a SpinChem ${ }^{\circledR}$ Rotating Bed Reactor
}

\author{
Tung Ngoc Pham ${ }^{1,2}$ - Ajaikumar Samikannu ${ }^{1}$ - Anne-Riikka Rautio ${ }^{3}$ • \\ Koppany L. Juhasz ${ }^{4} \cdot$ Zoltan Konya $^{4,5} \cdot$ Johan Wärnå $^{6} \cdot$ Krisztian Kordas $^{3}$ • \\ Jyri-Pekka Mikkola ${ }^{1,6}$
}

(C) Springer Science+Business Media New York 2016

\begin{abstract}
In this work the activity of ruthenium decorated carbon foam $(\mathrm{Ru} / \mathrm{CF})$ catalyst was studied in three phase hydrogenation reaction of D-xylose to D-xylitol. The developed catalyst was characterized by using scanning electron microscopy, transmission electron microscopy, X-ray photoelectron spectroscopy, inductively coupled plasma optical emission spectrometry and nitrogen adsorption-desorption measurement. Kinetic measurements were carried out in a laboratory scale pressurized reactor $\left(\right.$ Parr $\left.^{\circledR}\right)$ assisted by SpinChem ${ }^{\circledR}$ rotating bed reactor (SRBR), at pre-defined conditions (40-60 bar $\mathrm{H}_{2}$ and $100-120{ }^{\circ} \mathrm{C}$ ). The study on the influence of reaction conditions showed that the conversion rate and selectivity of hydrogenation reaction of Dxylose was significantly affected by temperature. These results have been proved by a competitive kinetics model which was found to describe the behavior of the novel
\end{abstract}

Jyri-Pekka Mikkola

Jyri-Pekka.Mikkola@umu.se

1 Technical Chemistry, Department of Chemistry, ChemicalBiological Centre, Umeå University, 90187 Umeå, Sweden

2 Department of Chemistry, The University of Danang, Danang University of Science and Technology, 54 Nguyen Luong Bang, Da Nang, Lien Chieu, Vietnam

3 Microelectronics and Materials Physics Laboratories, Department of Electrical Engineering, University of Oulu, P.O. Box 4500, 90014 Oulu, Finland

4 Department of Applied and Environmental Chemistry, University of Szeged, Rerrich Béla tér 1., Szeged 6720, Hungary

5 MTA-SZTE Reaction Kinetics and Surface Chemistry Research Group, Rerrich Béla tér 1., 6720 Szeged, Hungary

6 Industrial Chemistry \& Reaction Engineering, Department of Chemical Engineering, Process Chemistry Centre, Ảbo Akademi University, 20500 Åbo-Turku, Finland system $(\mathrm{Ru} / \mathrm{CF}$ catalyst used together with the SRBR) very well. Besides, it was revealed that the catalytic activity as well as the stability of our Ru/CF-SRBR is comparable with the commercial ruthenium decorated carbon catalyst $(\mathrm{Ru} /$ AC) under identical reaction conditions. Moreover, all steps from catalyst preparation and catalyst recycling as well as catalytic testing can be performed in an easy, fast and elegant manner without any loss of materials. Briefly, the developed $\mathrm{Ru} / \mathrm{CF}$ catalyst used together with the SRBR could be used an excellent alternative for the conventional Raney nickel catalyst in a slurry batch reactor and offers an attractive concept with obvious industrial applicability.

Keywords D-xylose $\cdot$ D-xylitol $\cdot$ Ruthenium $\cdot$ Carbon foam $\cdot$ SpinChem $\cdot$ Rotating bed reactor

\section{Introduction}

Recently, in line with the current trends in chemical industry, researchers have been putting a lot of effort into developing efficient methods for the production of chemicals from the renewable feedstocks. D-xylitol, a five-carbon pentose sugar alcohol, has been recognized as one of the top-twelve value-added chemicals that can be obtained from biomass [1]. This water soluble sweetener with a higher sweetness but lower energy content than sucrose is particularly welcomed by health and weight conscious consumers. Moreover, due to the low insulin requirements and anti-caries properties, D-xylitol also finds other commercial applications in different markets such as pharmaceuticals and related dental products [2, 3]. Nowadays, D-xylitol can be found in daily consumer products such as chocolates, chewing gums, oral hygiene products, toothpastes, mouth fresheners and more $[4,5]$. A survey by 
Research and Markets ${ }^{\circledR}$ showed that the annual D-xylitol market is estimated at 161.5 thousand metric tons corresponding to about US\$670 million in 2013 and expected is to reach 242 thousand metric tons by 2020 [6].

Like other sugar alcohols, D-xylitol is produced via the hydrogenation reaction of the corresponding sugar (D-xylose). Traditionally, the reaction takes place in a batch reactor but also e.g. loop reactor installations exist. The reaction is carried out at high pressure and high temperature over Raney nickel (Ra-Ni) or supported ruthenium catalysts. Although the use of Ra-Ni is advantageous in terms of its low price and excellent catalytic activity [7, 8], relative fast deactivation and leaching of toxic nickel [7, 9] are major drawbacks of this type of catalysts. Supported Ru catalysts are advantageous due to its excellent selectivity and slower deactivation rate and has been considered as a promising alternative to $\mathrm{Ra}-\mathrm{Ni}$ catalyst $[9,10]$. Upon searching for materials with higher activity and selectivity, several types of supported $\mathrm{Ru}$ catalyst like $\mathrm{TiO}_{2}, \mathrm{NiO}$ modified $\mathrm{TiO}_{2}$, zeotype materials and activated carbon have been investigated $[8,10-12]$. Nevertheless, the use of powder form catalysts that are dispersed as slurries often results in production of fine particles due to mechanical wear of particles. Consequently, expensive separation and purification steps are required to obtain a clean final product and to recover the catalyst. Moreover, significant loss of catalyst as fine particles is easily occurring.

Herein we introduce a novel support, flexible carbon foam (pyrolyzed melamine) on which $\mathrm{Ru}$ has been immobilized. Moreover, the foam was immobilized in a SpinChem ${ }^{\circledR}$ rotating bed reactor (SRBR) (Fig. 1a) during the hydrogenation D-xylose experiments. Originating from melamine foam, the 3D-structured carbon foam possesses a lot of interesting properties such as good electrical conductivity, low density, high compressibility and surface area as well as high concentration of functional groups such as carboxylic and hydroxyl groups on its surface thus rendering the immobilization of metal nano-particles straightforward [13]. The aforementioned characteristics allow the carbon foam to be adapted to various purposes, ranging from electrical to chemical applications. In our previous study we have shown the possibility to use these carbon foams as catalyst support in a gas phase reaction among other applications [13]. In this study, the carbon foam again demonstrates its applicability as a support for ruthenium clusters in three-phase hydrogenation of D-xylose. Further, the applicability of SRBR technology as a feasible technology concept in three phase hydrogenations was demonstrated. The SRBR which can be considered as an evolution version of a stirred contained solid reactor [14] was recently developed by SpinChem AB, Umeå, Sweden. When rotating, the SRBR takes advantage of centrifugal forces that generate a flux through a solid catalyst located at the internal parts of the reactor. This type of operations not only provides good isothermal conditions but also improves the liquid-solid and gas-liquid mass transfer to the solid phase of the catalytic sites. Several studies have shown that the use of SRBR gives rise to enhanced mass transfer, minimized production of fine particles caused by mechanical grinding effects, eliminates any filtration steps and prevents loss of reagents $[15,16]$.

\section{Materials and Methods}

\subsection{Materials}

A batch autoclave (Parr) equipped with an electric heater, an internal thermocouple and a mechanical stirrer affixed to a SRBR S2x $\left(\right.$ SpinChem $^{\circledR}$ is a registered trademark owned
Fig. 1 a SRBR with Parr ${ }^{\circledR}$ reactor (big picture) and inside structure of SRBR with Ru/CF catalyst (small picture), b SRBR patterns and $\mathbf{c}$ The final solution of $\mathrm{Ru} / \mathrm{CF}-\mathrm{SRBR}$ (left) and $\mathrm{Ru} /$ AC used without SRBR (right)

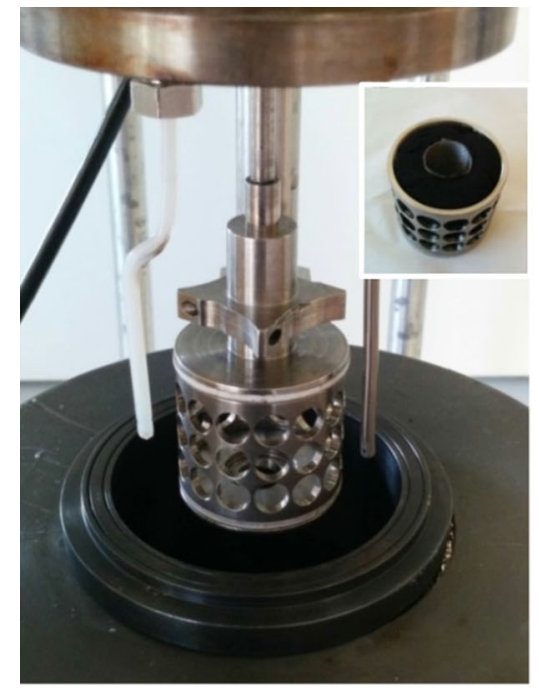

(a)

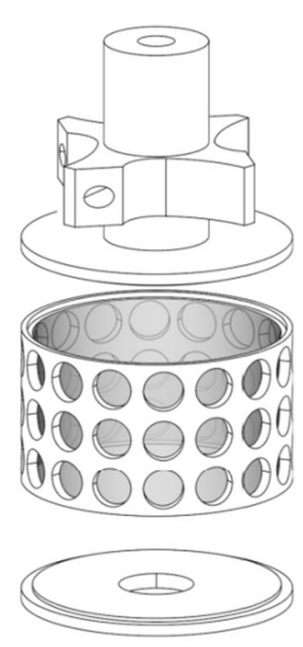

(b)

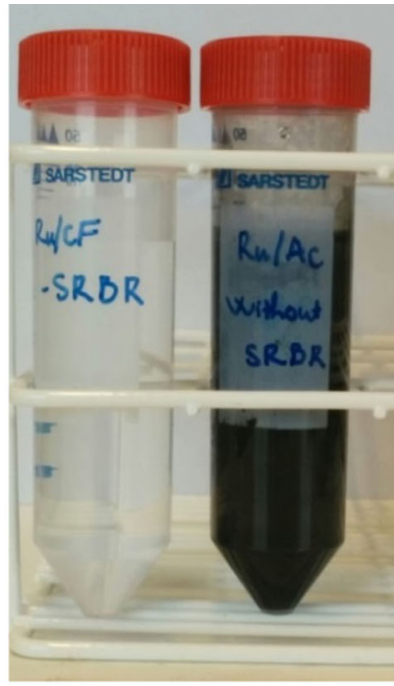

(c) 
by SpinChem AB, Umeå, Sweden) was used in this study. Melamine foam (Basotect ${ }^{\circledR} \mathrm{G}$ ) was purchased from BASF ${ }^{\circledR}$ company. Ruthenium (III) chloride hydrate $(99.9 \%$, $36 \% \mathrm{Ru}$ ) was purchased from ABCR GmbH. Commercial ruthenium catalyst (ruthenium, $5 \mathrm{wt} \%$ on carbon) was purchased from Aldrich Chemical company. Sodium borohydride $\left(\mathrm{NaBH}_{4}\right)$ was purchased from Fisher Scientific. Sodium hydroxide $(98.4 \%)$ was purchased from VWR. D-Xylose (>99\%) was purchased from Sigma Aldrich. The chemicals were used as received.

\subsection{Synthesis of Carbon Foam}

The carbon foam was synthesized as reported in detail in Ref. [13]. Briefly, melamine-based polymer foam (BASF, Basotect ${ }^{\circledR} \mathrm{G}$, used as received) was pyrolyzed at $800{ }^{\circ} \mathrm{C}$ ( $1 \mathrm{~h}$ with the ramping rate of $1{ }^{\circ} \mathrm{C} / \mathrm{min}$ ) in a quartz reactor under $\mathrm{N}_{2}$ flow $(50 \mathrm{ml} / \mathrm{min})$, followed by an activation process at $800{ }^{\circ} \mathrm{C}$ with $\mathrm{CO}_{2}(1 \mathrm{ml} / \mathrm{min}, 2 \%$ by volume in $\mathrm{N}_{2}$ ) for $2 \mathrm{~h}$. After completed pyrolysis/activation process, the system was allowed to cool to ambient temperature. Before use, the foam was washed several times with deionized water to remove traces of sodium (present in the polymer precursor) on the foam surface and then dried overnight in oven at $100{ }^{\circ} \mathrm{C}$.

\subsection{Catalyst Synthesis and Activity Testing}

\subsubsection{Catalyst Preparation}

Before commencing the sugar hydrogenation experiments, $\mathrm{Ru}$ decorated carbon foams ( $\mathrm{Ru} / \mathrm{CF})$ were synthesized. In a typical process, $0.2 \mathrm{~g}$ of activated carbon sponge was inserted into the SRBR. Next, a $200 \mathrm{ml}$ water solution of $\mathrm{RuCl}_{3}$ corresponding to around $150 \mathrm{ppm}$ as the initial concentration of $\mathrm{Ru}^{3+}$, was circulated through the foam for $24 \mathrm{~h}$ (SRBR stirring speed of $400 \mathrm{rpm}$ ). To determine the amount of $\mathrm{Ru}^{3+}$ adsorbed into the pores of the carbon foam, the solutions (before and after impregnation) were diluted 10 times in $2 \% \mathrm{HNO}_{3}$ and measured by using Inductively Coupled Plasma Optical Emission Spectrometer (ICP-OES). The catalyst was washed several times by water followed by reducing with aqueous solution of $\mathrm{NaBH}_{4}$. Generally, catalyst located inside the SRBR was immersed into a solution containing $150 \mathrm{ml}$ deionized water, followed by drop-wise addition of $20 \mathrm{ml}$ of $0.1 \mathrm{~g}$ $\mathrm{NaOH}$ and $0.2 \mathrm{~g} \mathrm{NaBH}_{4}$ in deionized water (in $30 \mathrm{~min}$ ) under stirring (approx. $200 \mathrm{rpm}$ ). After completed reaction, the catalyst was first washed several times with water until neutral $\mathrm{pH}$ followed by an additional washing with acetone. Finally, the catalyst was dried in vacuum oven overnight at $50{ }^{\circ} \mathrm{C}$.
In a reference experiment, the performance of $0.12 \mathrm{~g}$ of commercial ruthenium catalyst $(\mathrm{Ru} / \mathrm{AC})$ containing similar amount of ruthenium (around $6 \mathrm{mg}$ ) as our tailor-made $\mathrm{Ru} /$ $\mathrm{CF}$ catalyst (Ru, $3 \mathrm{wt} \%)$ was compared.

\subsection{Catalyst Recycling}

Catalyst recycling was simply performed by removing the SRBR from the reactor vessel and washing it several times with water in a beaker under stirring. Then, before the next catalytic cycle, the $\mathrm{Ru} / \mathrm{CF}$ residing inside the SRBR compartment was reduced with $\mathrm{NaBH}_{4}$ followed by washing and drying steps as described above.

\subsubsection{Reactor Setup}

Hydrogenation of D-xylose was carried out in a Parr reactor of $300 \mathrm{ml}$ nominal volume equipped with a mechanical stirrer affixed to a SRBR acting as catalyst holder and stirrer (Fig. 1a). The SRBR $(\phi 3.6 \times 3.5 \mathrm{~cm})$ consists of a hollow cylinder $(\phi 3.2 \times 2.9 \mathrm{~cm})$ equipped with rounded orifices at the sides (Fig. 1b) to allow liquid flux across the carbon foam catalyst. For reference experiments, instead of a SRBR, a stainless steel stirrer was used and a $7 \mu \mathrm{m}$ sintered metal filter was connected to the sampling line in order to avoid any loss of catalyst.

\subsubsection{Catalytic Experiments}

In a typical hydrogenation batch, $150 \mathrm{ml}$ solution of $7.5 \mathrm{~g}$ of D-xylose in deionized water was transferred to the reactor. As the next step, the reactor was purged several times with nitrogen to remove any oxygen residing in the reactor. Consequently, the sugar solution was bubbled with nitrogen for $20 \mathrm{~min}$, followed by bubbling with hydrogen (15 min). After adjusting the pressure to the pre-set value, the heater was turned on and the stirring was engaged $(500 \mathrm{rpm})$. Further, in order to ensure operations at the kinetic regime and any external mass-transfer limitations, various stirring rates were tried to pinpoint the minimum required stirring speed of the SRBR. Small samples of the reaction solution were periodically withdrawn for the HPLC analyses (around $0.5 \mathrm{ml}$ each).

\subsection{Analytical Methods}

The reaction products were analyzed using an HPLC (HP 1100 Series LC) equipped with an Aminex HPX-87C $(300 \times 7.8 \mathrm{~mm})$ carbohydrate column and refractive index detector. Aqueous solution of $\mathrm{CaSO}_{4} 1.2 \mathrm{mmol} \mathrm{L}^{-1}$ was used as an eluent for the analysis at flow rate of $0.4 \mathrm{ml} \mathrm{min}{ }^{-1}$ at $80{ }^{\circ} \mathrm{C}$. Nitrogen adsorption-desorption measurement were conducted for the prepared catalysts 

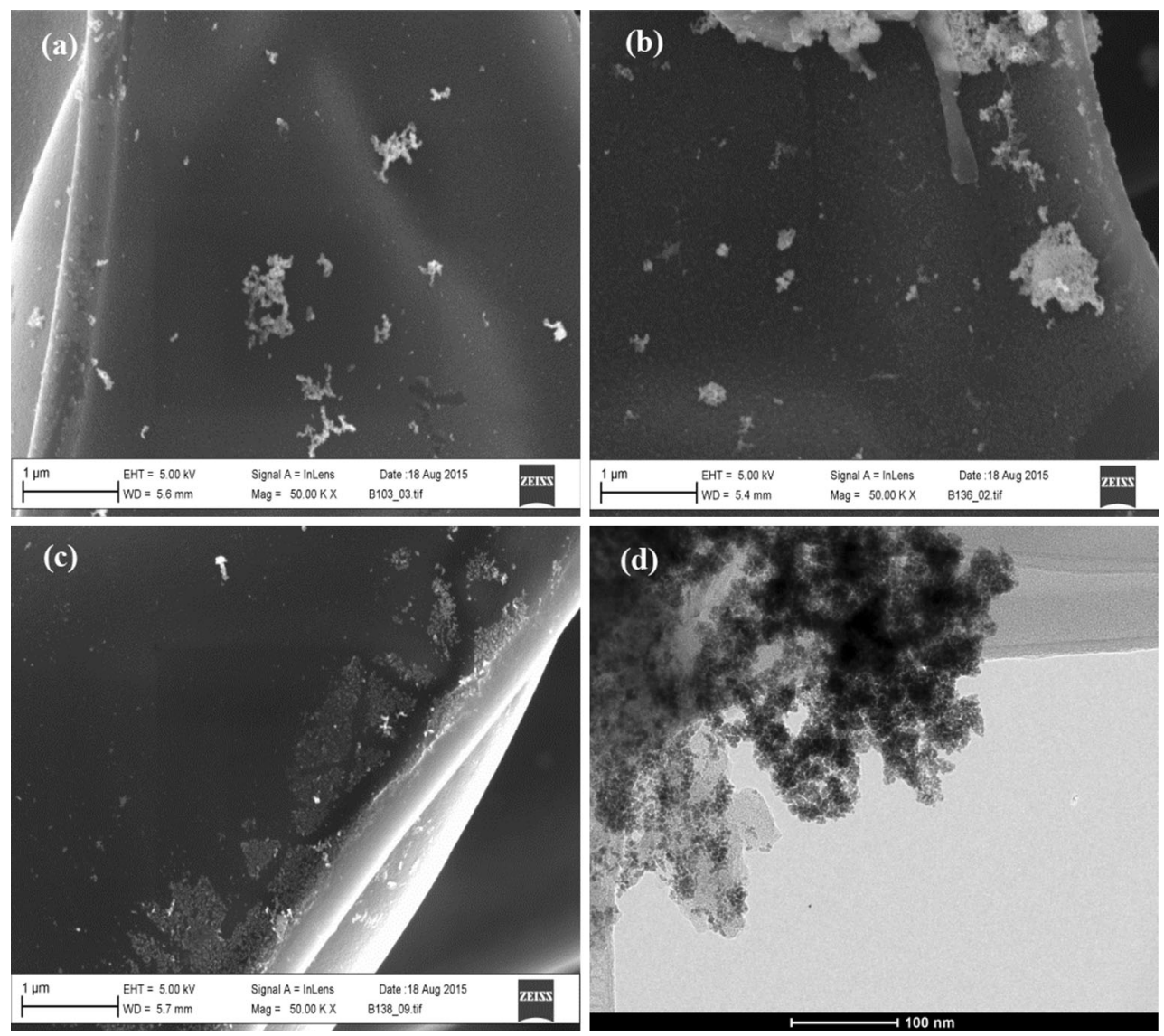

Fig. 2 SEM images of: a Fresh Ru/CF catalyst, b Spent Ru/CF-SRBR catalyst after 15 recycling times, c Spent Ru-/F catalyst used without SRBR and d TEM images of Ru/CF fresh catalyst

using a Tristar 3000 (Micromeritics, GA, USA). Adsorption-desorption isotherms were recorded at $77 \mathrm{~K}$ after degassing the samples at $393 \mathrm{~K}$. The surface areas were calculated by the BET method and pore volumes were calculated from the corresponding desorption isotherm. The chemical state of the catalytic species on the support was examined by means of X-ray photoelectron spectroscopy (XPS) technique (Axis Ultra DLD spectrometer with a monochromatized $\mathrm{Al} \mathrm{K} \alpha \mathrm{X}$-ray source with charge neutralization). Processing of the spectra was accomplished with the Kratos software. The microstructure of the specimens were studied by field emission scanning electron microscopy (FESEM, Zeiss Ultra plus at $5 \mathrm{kV}$ ). The morphology of the prepared ruthenium catalyst on the carbon foam support was measured by transmission electron microscopy (TEM, Tecnai G2 20 X-Twin microscope with a tungsten thermionic cathode operated at an accelerating voltage of $200 \mathrm{kV}$ ). The content of ruthenium element in the samples was detected by using an ICP-OES Optima 2000 DV (Perkin Elmer Instruments). In order to obtain the calibration curve, the blank and four points were used and the standards $(0.1,1,10$ and $100 \mathrm{ppm})$ were prepared from $1000 \mathrm{ppm}$ stock solutions and diluted with $2 \% \mathrm{HNO}_{3}$.

\section{Results and Discussion}

\subsection{Catalyst Characterization Results}

In this study, monolithic activated carbon foam (A800) with a ruthenium content of $3 \mathrm{wt} \%$ was employed as the catalyst (determined by ICP-OES). The TEM and SEM studies revealed that besides small $\mathrm{Ru}$ clusters around $10 \mathrm{~nm}$ in diameter, also bigger clusters of ruthenium was found on the carbon foam surface (Fig. 2). The binding energies (BE) of $\mathrm{Ru} 3 \mathrm{~d}_{5 / 2}$ obtained by XPS for all the catalysts were found to reside around $280.2-282.3 \mathrm{eV}$ which can be attributed to the presence of Ru on the surface of carbon foam (Fig. 3). The peak at BE of $280.2 \mathrm{eV}$ can be assigned to metallic ruthenium. This value is in agreement with previously reported values and it has been pointed out that the $\mathrm{BE}$ for $\mathrm{Ru}^{0}$ is ranging between 279.96 and $280.3 \mathrm{eV}$ [17, 18]. Similarly, the two peaks at 280.9 

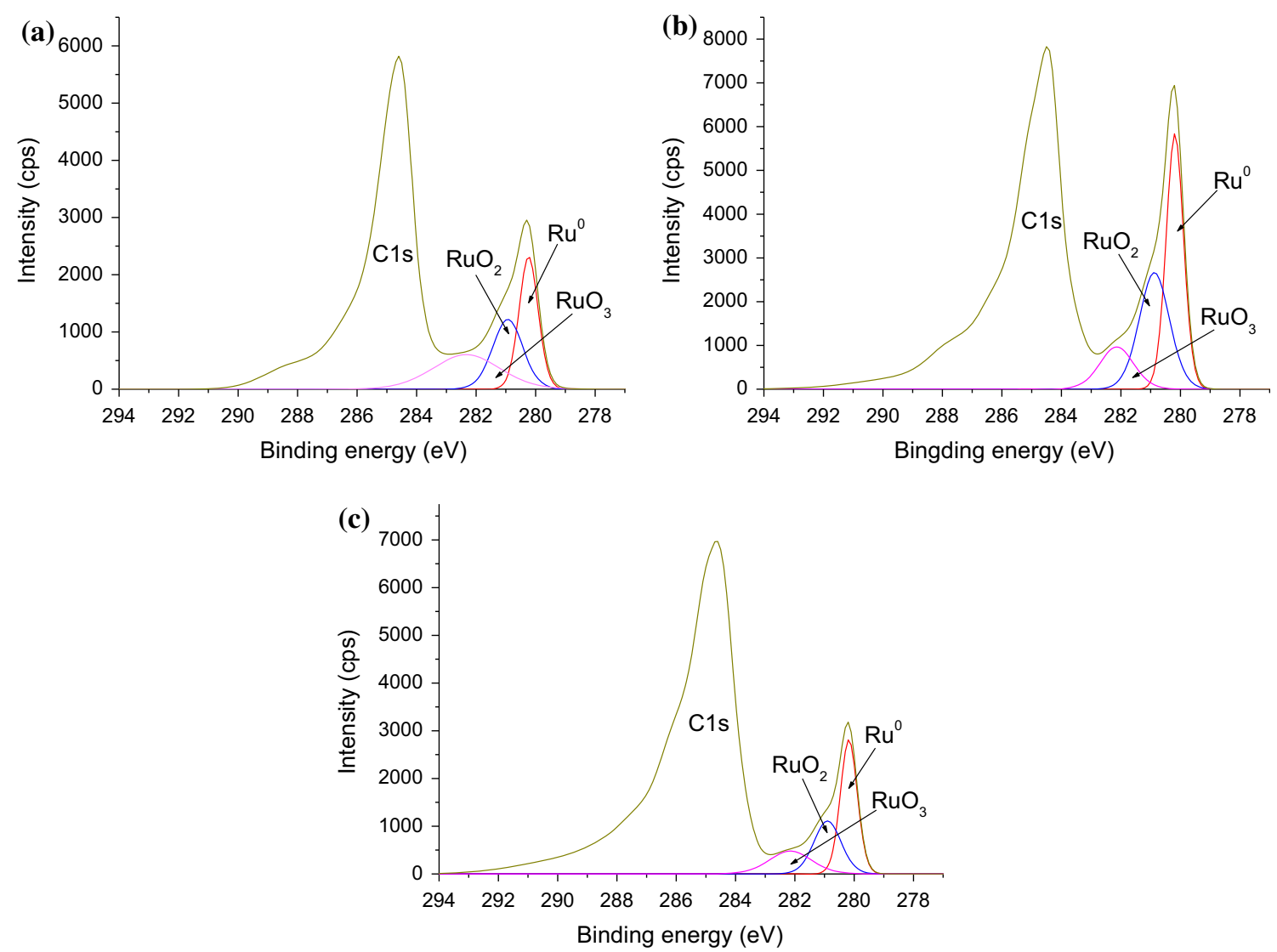

Fig. 3 XPS results of: a fresh Ru/CF catalyst, b spent Ru/CF catalyst after 15 recycling times with SRBR and $\mathbf{c}$ spent Ru/CF catalyst without SRBR

Table 1 Catalyst characterization results

\begin{tabular}{llllll}
\hline & Carbon foam (CF) & Fresh Ru/CF catalyst & Spent Ru/CF catalyst ${ }^{\mathrm{a}}$ & Spent Ru/CF catalyst $^{\mathrm{b}}$ & Ru/AC (5 \%) (fresh) \\
\hline BET surface area $\left(\mathrm{m}^{2} \mathrm{~g}^{-1}\right)$ & $>300$ & 81 & 30 & 44 & 711 \\
$\mathrm{Ru}($ at.\%) & - & 5.9 & 5.4 & 2.3 & - \\
$\mathrm{Ru}$ contain (wt\%) & - & 3 & - & - & 5 \\
\hline
\end{tabular}

${ }^{a}$ After 15 recycling rounds with SRBR

b After running without SRBR

Table 2 Study of leaching property of different catalysts

\begin{tabular}{lll}
\hline & Precursors & Leaching $(\mathrm{ppm})$ \\
\hline $\mathrm{Ru} / \mathrm{CF}$ & $\mathrm{RuCl}_{3}$ & $<0.1$ \\
$\mathrm{Ru} / \mathrm{AC}$ & - & $<0.1$ \\
$\mathrm{Ru} / \mathrm{NiO}-\mathrm{TiO}_{2}[8]$ & $\mathrm{RuCl}_{3}$ & 0.31 \\
\hline
\end{tabular}

and $282.3 \mathrm{eV}$ can be allocated as $\mathrm{RuO}_{2}$ and $\mathrm{RuO}_{3}$, respectively. These two types of ruthenium oxides can be formed by the oxidation of $\mathrm{Ru}$ metal when exposed to air.
As observed from BET measurements, the specific surface area of the carbon foam changed upon the metal decoration process. Consequently, a decrease in the surface area from more than $300 \mathrm{~m}^{2} \mathrm{~g}^{-1}$ (carbon foam) to around $81 \mathrm{~m}^{2} \mathrm{~g}^{-1}(\mathrm{Ru} / \mathrm{CF})$ could be observed due to partial blockage of the pores by $\mathrm{Ru}$ clusters and also maybe by water strongly trapped inside small pores of the foam. When the very similar fresh catalyst sample was treated at higher temperatures and longer time periods (at $200{ }^{\circ} \mathrm{C}$ for $4 \mathrm{~h}$ ) than the standard conditions $\left(120^{\circ} \mathrm{C}, 2 \mathrm{~h}\right)$, the surface area was increased to $130 \mathrm{~m}^{2} \mathrm{~g}^{-1}$. This might indicate the presence of trapped water inside the fresh catalyst. After 15 

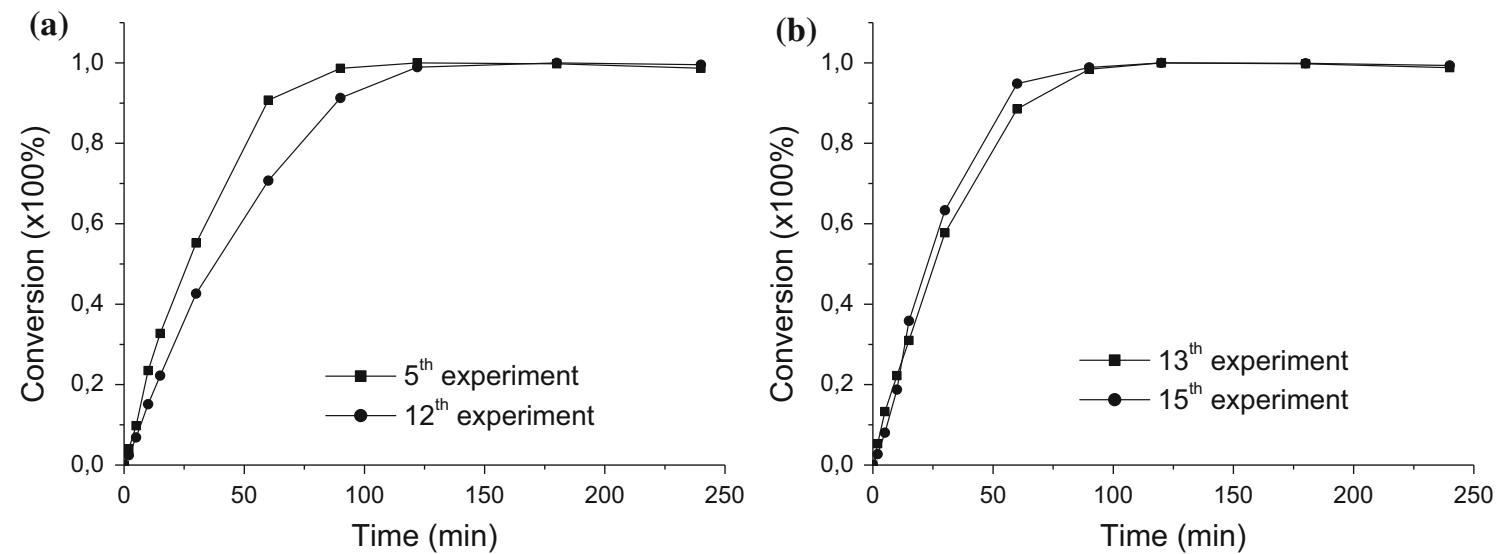

Fig. 4 Catalyst deactivation studies at the identical reaction conditions (reaction temperature: $110{ }^{\circ} \mathrm{C}$, pressure: 50 bar) with SRBR: a two distant experiments (SRBR speed: $500 \mathrm{rpm}$ ) and a two close experiments (SRBR speed: $700 \mathrm{rpm}$ )

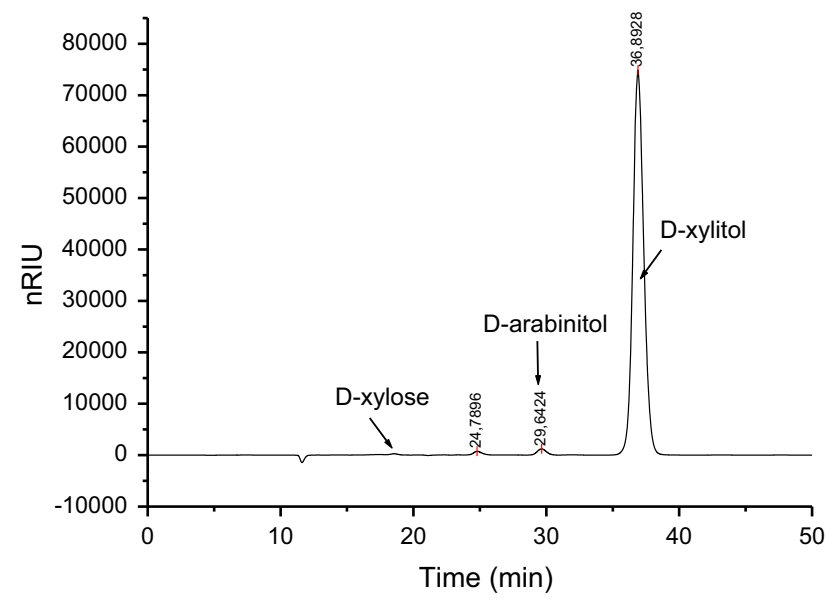

Fig. 5 A typical HPLC chromatogram of product and byproducts. Reaction condition: temperature $=120^{\circ} \mathrm{C}$, pressure $=50$ bar, SRBR stirring speed $=500 \mathrm{rpm}$ and sampling time $=90 \mathrm{~min}$

recycling cycles, the surface area of the spent $\mathrm{Ru} / \mathrm{CF}$ catalyst was further decreased to around $30 \mathrm{~m}^{2} \mathrm{~g}^{-1}$ (Table 1). As can be seen, (Fig. 2a, b, respectively), the spent catalyst contained larger Ru clusters due to the agglomeration of metal. In a study about the sintering mechanism of Pt on graphitized carbon, Kinoshita and his co-worked showed that noble metal particles can agglomerate to form bigger particles at $\left(100-200{ }^{\circ} \mathrm{C}\right)$, in a liquid phase environment
[19]. Moreover, another report showed that under hydrogen atmosphere, the sintering of noble metal was more pronounce compared with nitrogen and oxygen atmospheres [20]. Thus, agglomeration of ruthenium particles might also occur under the hydrogenation conditions. Further, fouling, i.e. accumulation of heavy side-products, inside the pores contributes to the pore blocking and, consequently, further reduces the surface area [21].

\subsection{Metal Leaching and Catalyst Deactivation}

The leaching of $\mathrm{Ru}$ was monitored upon each batch and analyzed by ICP-OES. A negligible amount of ruthenium (less than $0.1 \mathrm{ppm}$ ) was detected clearly demonstrating that the leaching is present but very minor. Furthermore, when analyzing the fresh and spent catalyst (after 15 recycling rounds, Table 1) by XPS, it was seen that the amount of Ru was virtually the same. Moreover, as can be seen from Table 2, the extent of ruthenium leaching in our catalyst $(\mathrm{Ru} / \mathrm{CF})$ is equal with commercial $\mathrm{Ru} / \mathrm{AC}$ and lower than $\mathrm{NiO}$ modified $\mathrm{TiO}_{2}$ supported ruthenium catalyst [8] thus, further indicating good stability of the developed $\mathrm{Ru} / \mathrm{CF}$ catalyst.

Throughout the experimental matrix, the same $\mathrm{Ru} / \mathrm{CF}$ catalyst was used (15 runs at various reaction conditions). Thus, control experiments, at predefined reaction condition were used to quantify the catalyst deactivation. For
Fig. 6 a The reaction scheme and $\mathbf{b}$ Fisher projections of D-xylose, D-xylitol, Darabinitol and D-xylulose

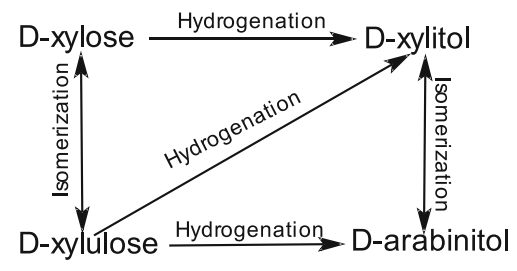

(a)



D-xylose

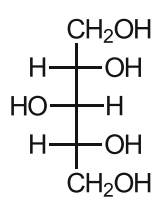

D-xylitol

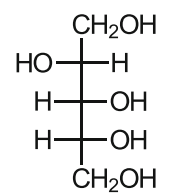

D-arabinitol

(b)

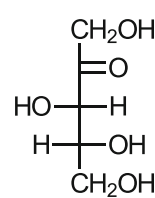

D-xylulose 

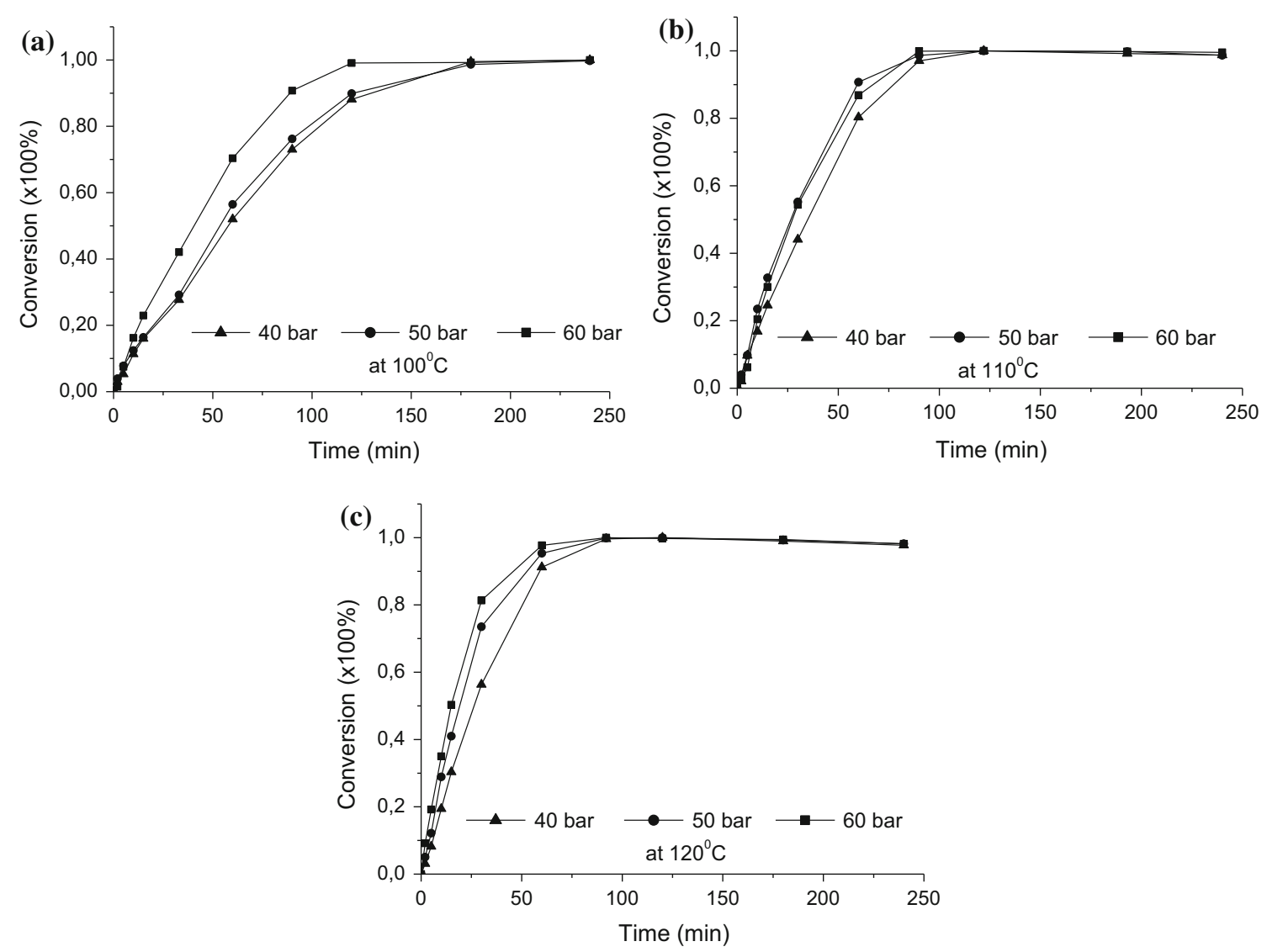

Fig. 7 Influence of hydrogen pressure on the hydrogenation rates at: a $100{ }^{\circ} \mathrm{C}, \mathbf{b} 110{ }^{\circ} \mathrm{C}$ and $\mathbf{c} 120{ }^{\circ} \mathrm{C}$. (Catalyst: Ru/CF, SRBR speed: $500 \mathrm{rpm}$ )

example, when comparing two runs (the 5 th and 12 th experiments) only a marginal decreasing in the reaction rate can be observed (Fig. 4a). Further, the plausible reason for reduced activity is catalyst deactivation (agglomeration and fouling). Furthermore, since no reduction in the activity was observed between Run13 and Run15 (Fig. 4b) we can conclude that the catalyst deactivation is very slow. Overall, we can thus claim that the Ru/CF catalyst exhibits good stability under studied reaction conditions.

\subsection{Qualitative Kinetics}

The hydrogenation of D-xylose, in principle, is straight forward; however the formation of small amounts of by-products is usually observed. Depending on the reaction conditions, different by-products can be formed such as: Dxylonic acid through alkali-catalyzed Cannizzaro reaction as well as formation rearrangement/isomerization products Dxylulose and D-arabinitol. In our case, besides the main product (D-xylitol), minor amounts of by-products also could be observed (Fig. 5). Upon identification of the by-products, similar protocol as in Ref. [7] was adopted. Consequently, the peak at $29.6 \mathrm{~min}$ (D-arabinitol) was confirmed as the byproduct present in highest concentration. The fact that no D- xylulose could be identified might imply that herein D-arabinitol can be was formed through D-xylitol isomerization [22] rather than through the hydrogenation of D-xylulose (Fig. 6a).

As always, selectivity towards the desired product and conversion are qualifications that determine the performance of a catalyst. Generally, the Ru/CF catalyst gave rise to high conversion of D-xylose (up to $99.7 \mathrm{wt} \%$ ) and high D-xylitol selectivity (up to 98.4 wt\%) (Fig. 7-10). However, upon high-pressure hydrogenation reactions, the conversion and selectivity are naturally dependent on pressure and temperature. The influence of the operating pressure on the conversion rate was revealed by varying the hydrogen pressure $(40,50$ and 60 bar) while maintaining constant reaction temperature. As can be seen (Fig. 7), the use of higher pressures generally resulted in slightly higher reaction rates. This observation is also in agreement with the studies of Sifontes et al. [23] and Wisniak et al. [24] that showed that when the hydrogen pressure exceeded $40 \mathrm{bar}$, the reaction rate is weakly to non-dependent on the hydrogen pressure. On the other hand, the effect of temperature on the reaction rate is more obvious (Fig. 8). The hydrogenation clearly proceeds faster with increasing temperature, especially when lower hydrogen pressures are 

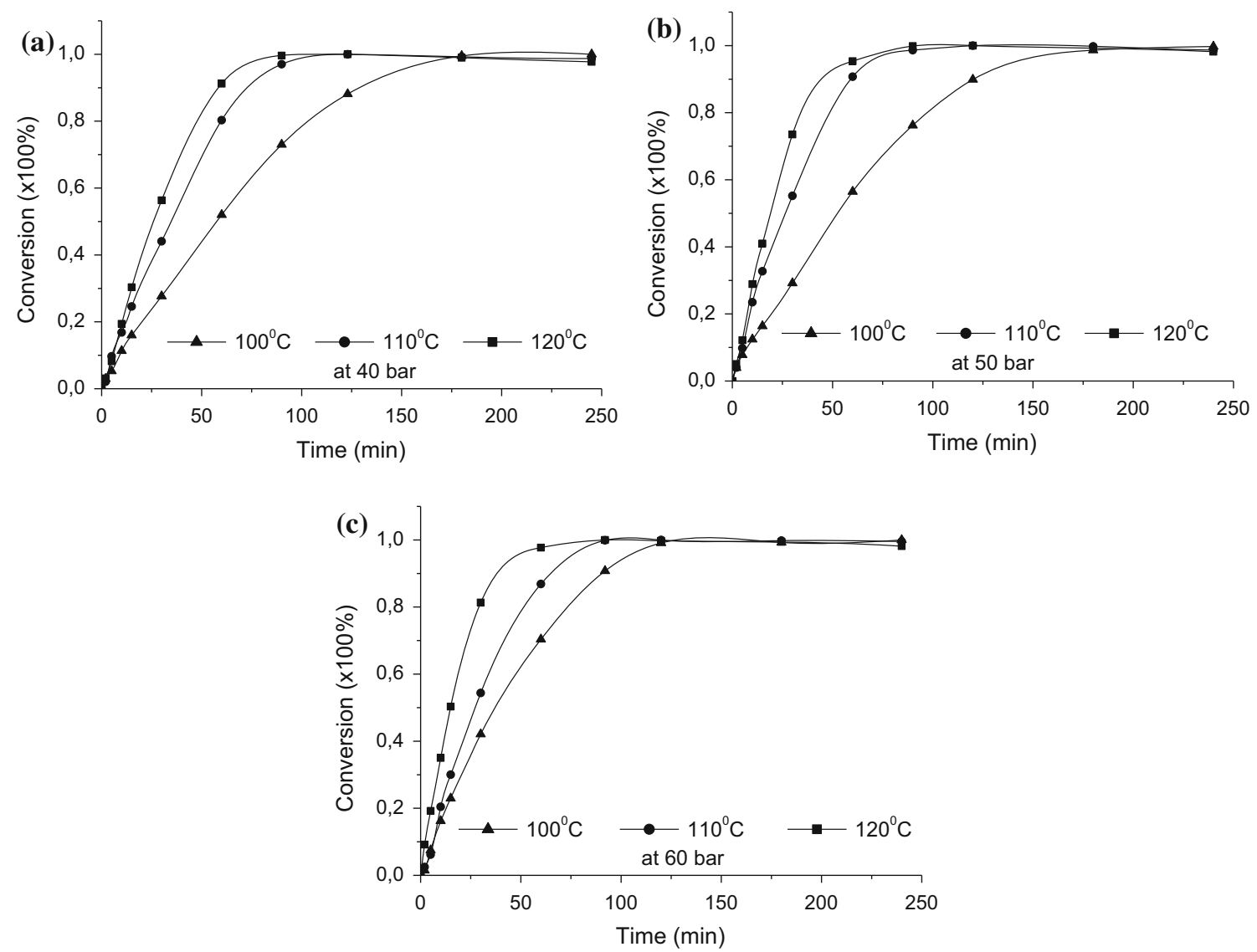

Fig. 8 Influence of reaction temperature on the hydrogenation rates at: a 40 bar, b 50 bar and c 60 bar. (Catalyst: Ru/CF, SRBR speed: 500 rpm)

applied. At constant pressure, twice longer reaction times were needed to reach the maximum conversion when the reaction temperature was decreased from 120 to $100{ }^{\circ} \mathrm{C}$.

As shows in Figures 9, 10, respectively, the selectivity towards the main product, D-xylitol, is dependent on the reaction conditions as well as the conversion of D-xylose. Generally, the selectivity towards D-xylitol increased with $\mathrm{D}$-xylose conversion reaching maximum at the conversion level of around $90 \%$. After that the selectivity towards Dxylitol starts to decline due to increased D-arabinitol formation. At higher temperatures, the selectivity towards Dxylitol was retarded even more (Fig. 10). However, the effect of pressure on the selectivity towards D-xylitol and Darabinitol is not significant (Fig. 9).

When comparing the performance of our catalyst $(\mathrm{Ru} /$ $\mathrm{CF}$ ) with commercial $\mathrm{Ru} / \mathrm{AC}$ under identical reaction conditions $\left(50\right.$ bar, $110^{\circ} \mathrm{C}$, Fig. 11a), it is obvious that the performance of our catalyst is on par with the commercial slurry catalysts in terms of both conversion and selectivity toward D-xylitol (after $90 \mathrm{~min}$ reaction, the measured selectivity is 98.2 and $98.7 \%$ for $\mathrm{Ru} / \mathrm{CF}$ and $\mathrm{Ru} / \mathrm{AC}$, respectively). Moreover, since the $\mathrm{Ru} / \mathrm{AC}$ catalyst was very fine powder, it was difficult to avoid any loss of catalyst even though very fine filter was installed in the sampling line. Therefore, after a reaction batch, filtration is the only way to recover the $\mathrm{Ru} / \mathrm{AC}$ catalyst - a tedious task that is time consuming and also contributes to the loss of catalyst. In contrast, the structured carbon foam catalyst is kept inside the SRBR that not only renders the catalyst recovery step simple but also gives a clean and clear product solution (Fig. 1c). Thus, it is evident that the concept of using structured catalysts gives clear advantages in terms of ease of operations and good product quality offering an excellent alternative to classical Ra-Ni catalyst upon large scale operations.

\subsection{Influence of the Stirring Rate}

In order to investigate the influence of the stirring rate on the reaction rate, hydrogenations were performed at different stirring speeds (300, 500 and $700 \mathrm{rpm})$. As can be seen (Fig. 11b), only slight improvement in the reaction rate was observed when the SRBR stirring speed was increased. Usually, when the stirring rate is increased, a higher reaction rate is achieved as the result of improved external mass-transfer. However, in a SRBR a faster flow 

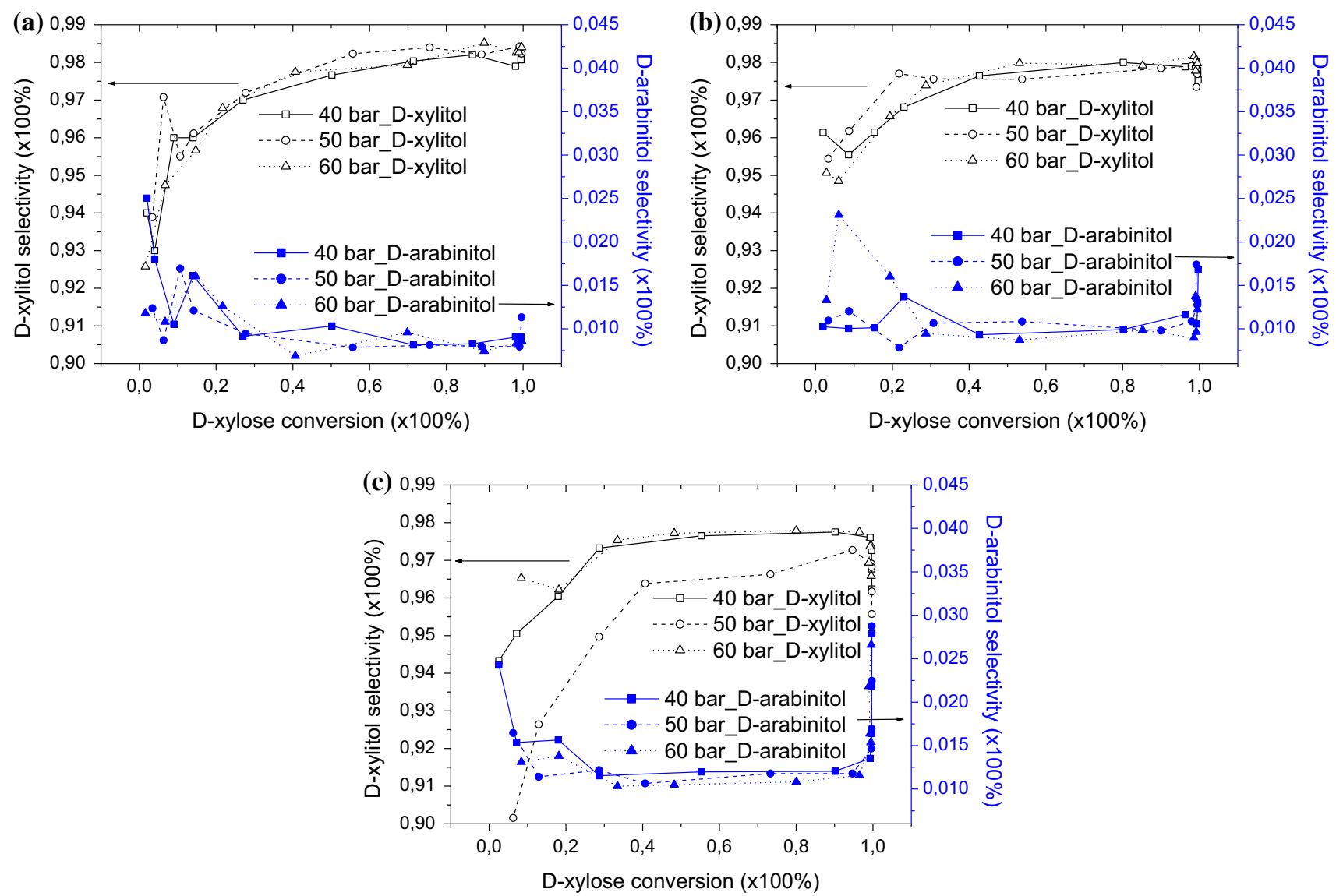

Fig. 9 Influence of hydrogen pressure and D-xylose conversion on the selectivity of D-xylitol and D-arabinitol at: a $100{ }^{\circ} \mathrm{C}, \mathbf{b} 110{ }^{\circ} \mathrm{C}$ and $\mathbf{c} 120$ ${ }^{\circ} \mathrm{C}$. (Catalyst: Ru/CF, SRBR speed: $500 \mathrm{rpm}$ )

rate through the catalyst matrix will partially also decrease the contact time between the reactant and the active sites of the catalyst. Moreover, as could be observed, at higher stirring rates, more gas bubbles $\left(\mathrm{H}_{2}\right)$ were formed in the reaction media limiting the accessibility of the liquid reactant to the active sites on the foam surface.

\subsection{Performance of the New System}

Traditional catalyst materials can possess characteristics which can lead to some drawbacks when using with SRBR such as: (a) For low density materials, due to the fixed capacity of the catalyst chamber of SRBR it can be a problem if higher catalyst bulk densities are desired; (b) For powder type catalyst material, in order to retain a powder catalyst within the SRBR, inner and an outer screen (metal meshes) is compulsory. These screens will retard the reactant flux through the catalyst material located inside the SRBR. Thus, for higher flow rates through the catalyst matrix, a higher stirring rate is required that, obviously, translates to higher energy consumption. Moreover, for catalyst formulations as very fine powders, immobilization is not possible. For example, to retain an activated carbon powder catalyst with the particle sizes in micron range, a screen with the mesh size smaller than 300 might be required. Unfortunately, screens with very small holes will result in the blocking of the screen rendering the SRBR concept unpractical. Consequently, our monolith-type, flexible $\mathrm{Ru} / \mathrm{CF}$ catalyst with high mechanical strength [13] can be seen as a solution. First, because of its flexibility, higher $\mathrm{Ru} / \mathrm{CF}$ catalyst loading (very low density of around $8 \mathrm{mg} \mathrm{cm}^{-3}$ ) can be obtained by pressing the foam into the SRBR. Consequently, in a typical reaction, $0.2 \mathrm{~g}$ of $\mathrm{Ru} / \mathrm{CF}$ (around $25 \mathrm{~cm}^{3}$ ) was easily forced inside the SRBR chamber (around $12 \mathrm{~cm}^{3}$ ). Secondly, once the catalyst is secured inside the SRBR, it cannot escape even at high stirring rates. Thus, neither inner nor outer screens are required.

On the other hand, it also became evident that the $\mathrm{Ru} / \mathrm{CF}$ catalyst was not operating well as a 'slurry' (after cutting into small pieces with the biggest dimension is less than $3 \mathrm{~mm}$ ). On the contrary, when residing inside the SRBR, the $\mathrm{Ru} / \mathrm{CF}$ catalyst gave rise to much higher reaction rate than as powder and, due to its very low density, the 

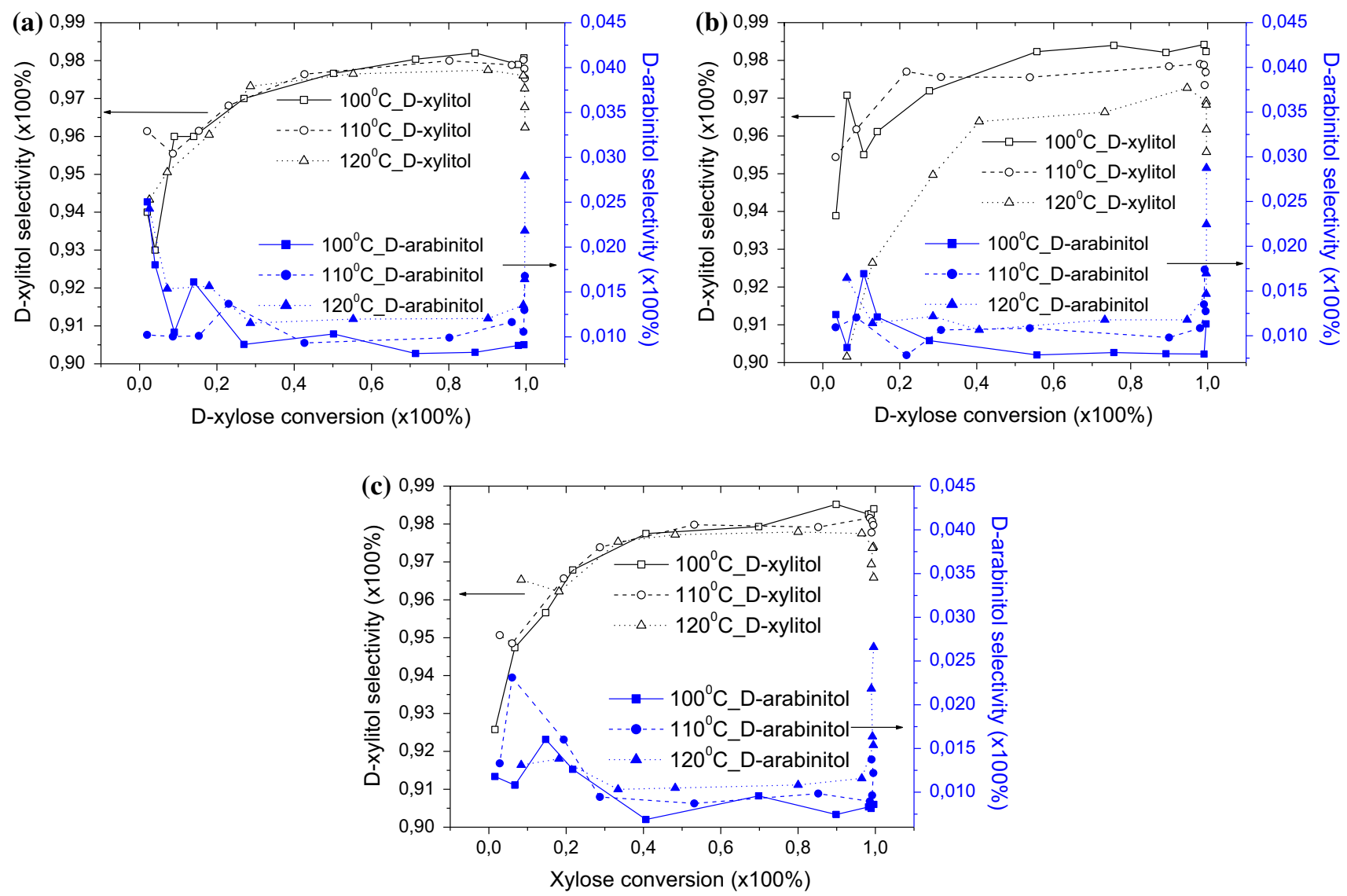

Fig. 10 Influence of reaction temperature and D-xylose conversion on the selectivity of D-xylitol and D-arabinitol at: a 40 bar, b 50 bar and $\mathbf{c} 60$ bar. (Catalyst: Ru/CF, SRBR speed: $500 \mathrm{rpm}$ )

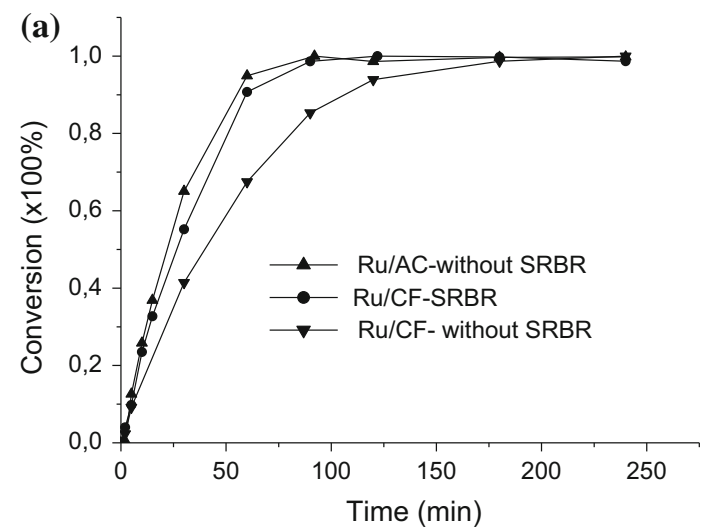

Fig. 11 a The catalytic performance of Ru/CF-SRBR $\left(\right.$ SpinChem ${ }^{\circledR}$ Rotating Bed Reactor) compared with $\mathrm{Ru} / \mathrm{AC}$ without SRBR and $\mathrm{Ru} /$ $\mathrm{CF}$ without SRBR at identical conditions (temperature: $110{ }^{\circ} \mathrm{C}$,

fragments of $\mathrm{Ru} / \mathrm{CF}$ catalyst travelled at more or less the same velocity as the liquid phase whereupon the flux inside the pore system should be seriously retarded. Therefore, the mass transfer inside the foam fragments becomes the rate limiting step seriously hampering the overall reaction

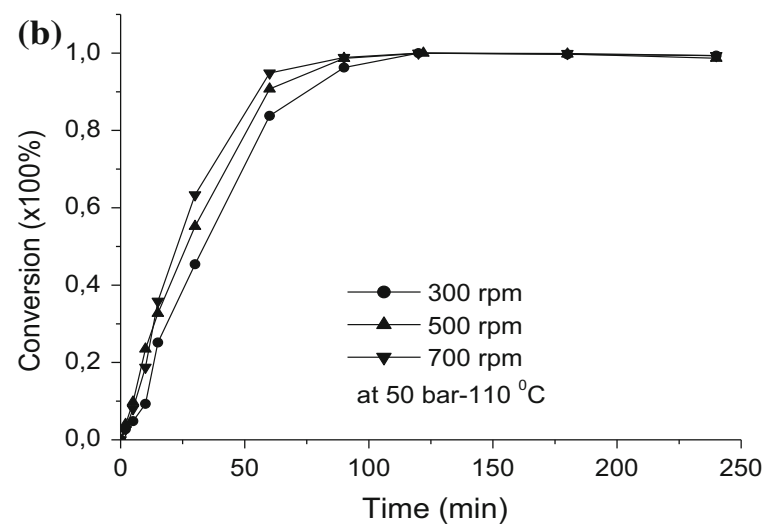

pressure: 50 bars and stirring rate: $500 \mathrm{rpm}$ ) and $\mathbf{b}$ The effect of SRBR stirring speed on the D-xylose conversion ( $\mathrm{Ru} / \mathrm{CF}$ catalyst, temperature: $110^{\circ} \mathrm{C}$ and pressure: 50 bars)

rate. Consequently, in SRBR, due to the centrifugal forces, an efficient flow of reactants through the catalyst matrix can easily be achieved. Also, as evidenced by XPS (Table 1) and SEM (Fig. 2c) results, when floating freely within the reaction media (mainly due to attrition by the 
Table 3 Estimated kinetic parameters, frequency factor $\mathrm{k}_{0}$, activation energy $\mathrm{E}_{\mathrm{a}}$ and adsorption coefficients $\mathrm{K}_{\mathrm{Xylose}}$ and $\mathrm{K}_{\mathrm{H} 2} ; \mathrm{T}_{\text {mean }}=110{ }^{\circ} \mathrm{C}$, degree of explanation $99.6 \%$

\begin{tabular}{llllll}
\hline & & Parameter value & Estimated standard error & Estimated standard error (\%) & Parameter/standard error \\
\hline $\mathrm{k}_{0}$ & $\mathrm{~mol} /\left(\mathrm{kg}_{\mathrm{cat}} \min \right)$ & $1.14 \times 10^{4}$ & $1.08 \times 10^{3}$ & 9.5 & 10.5 \\
$\mathrm{E}_{\mathrm{A}}$ & $\mathrm{J} / \mathrm{mol}$ & $5.31 \times 10^{4}$ & $1.11 \times 10^{3}$ & 2.1 & 47.9 \\
$\mathrm{~K}_{\mathrm{D}-\mathrm{xylose}}$ & $\mathrm{dm}^{3} / \mathrm{mol}$ & 1.53 & $1.03 \times 10^{-1}$ & 6.7 & 14.9 \\
$\mathrm{~K}_{\mathrm{H} 2}$ & $\mathrm{dm}^{3} / \mathrm{mol}$ & $2.82 \times 10^{1}$ & $2.54 \times 10^{1}$ & 90.1 & 1.1 \\
\hline
\end{tabular}
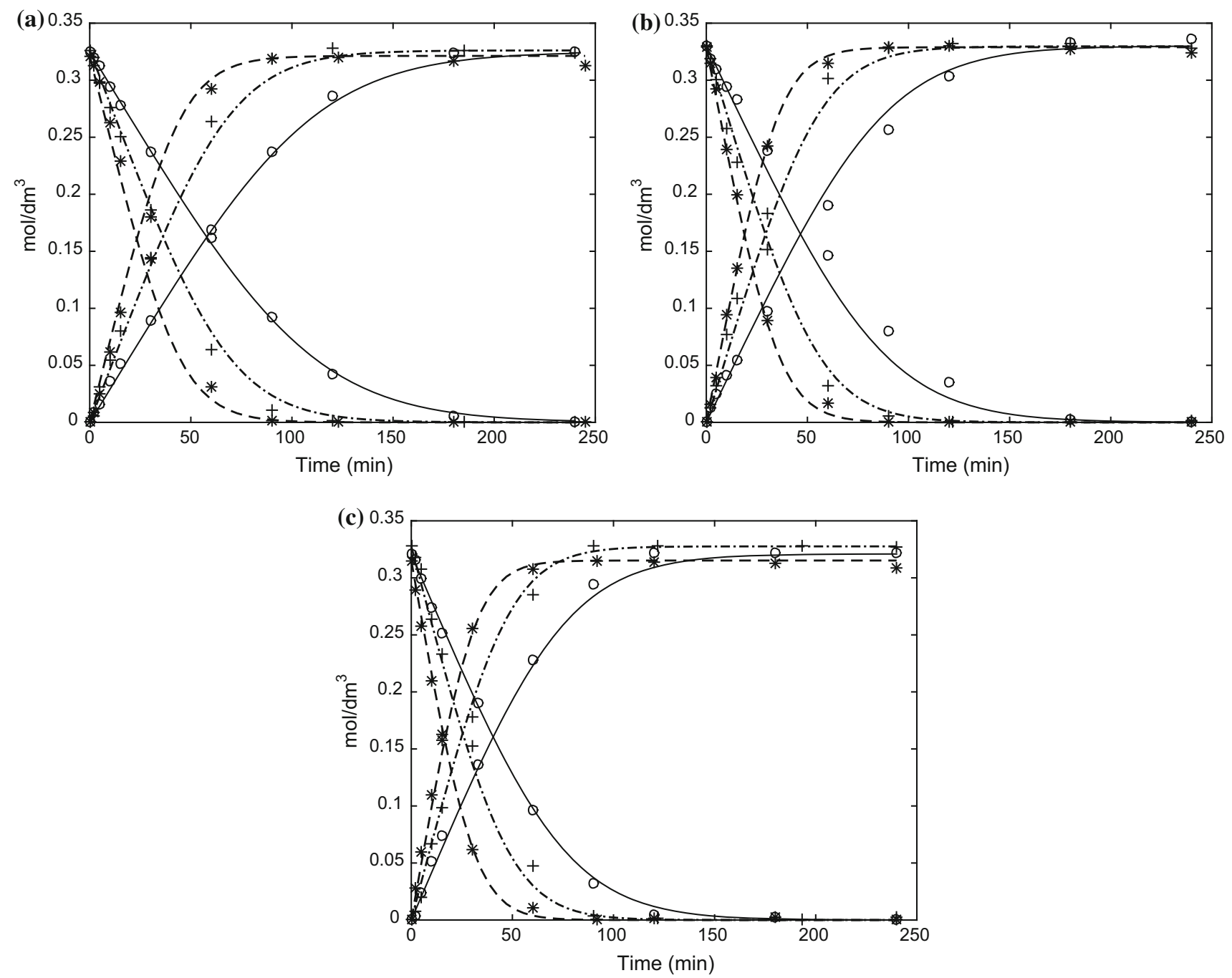

Fig. 12 Fitting of model to experimental data at a 40 bar, b 50 bar and c 60 bar and temperatures $100{ }^{\circ} \mathrm{C}$ (opencircle experiment, dashedline model), $110{ }^{\circ} \mathrm{C}$ (plus experiment,dashedline model) and $120^{\circ} \mathrm{C}$ (astrieks experiment, dashedline model)

stirrer), $\mathrm{Ru}$ is peeled off from the surface of the carbon foam when used as a 'slurry'. Due to these facts, an "in situ" strategy whereby the carbon foam was immobilized inside the SRBR through all steps from catalyst preparation (impregnation, washing and activation) to catalyst testing was adopted. As a result, the whole process can be performed in an easy, fast and elegant manner without any loss of materials. In case of slurry catalysts, recovery of catalyst by filtration is compulsory easily leading to loss of catalyst. It is very important to know that an amount of up to $8 \mathrm{wt} \%$ of Ru/AC catalyst can be lost after recuperation of catalysts from the filter $(0.45 \mu \mathrm{m}$ PES 
Table 4 Activation energy $\left(\mathrm{E}_{\mathrm{A}}\right)$ of different catalysts

\begin{tabular}{ll}
\hline Catalysts & $\mathrm{E}_{\mathrm{A}}(\mathrm{kJ} / \mathrm{mol})$ \\
\hline Ru/CF catalyst & 53.1 \\
Mo-supported Ra-Ni catalyst [7] & 53 \\
Zeolite Y (HYZ) supported ruthenium [27] & 46.8 \\
\hline
\end{tabular}

filter) [25]. Obviously, when a filtration step was needed, it was virtually impossible to perform 15 cycles of catalyst recycling which can easily be achieved upon use of $\mathrm{Ru} / \mathrm{CF}$ together with SRBR. Briefly, the developed Ru/CF catalyst used together with the SRBR offers an attractive concept with obvious industrial applicability.

\subsection{Modeling of the Reaction System}

A simplified model was concerned here to obtain a physical feeling of the behavior of the model and to illustrate the central features of the kinetics. For this work we found that a competitive model in D-xylose and hydrogen works well for the studied sugar hydrogenation process [24]. The formation rate of D-xylitol from D-xylose is described by equations:

$r=\frac{k c_{\text {Xylose }} c_{\mathrm{H}_{2}}}{\left(1+K_{\text {Xylose }} c_{\text {Xylose }}+\left(K_{\mathrm{H}_{2}} c_{\mathrm{H}_{2}}\right)^{0.5}\right)^{3}}$

The solubility of hydrogen in the sugar solution was calculated from a formula as a function of D-xylose, Dxylitol concentrations, temperature and hydrogen pressure [26]. The equation is based on experimental solubility measurements.

$$
\begin{aligned}
x_{H_{2}}= & \frac{c_{x y l o s e}}{c_{\text {xylose }}+c_{\text {xylitol }}}\left[\ln (0.9991)-\frac{0.1144}{T}+0.0004228 \ln \left(P_{H_{2}}\right)\right] \\
& +\frac{c_{\text {xylitol }}}{c_{\text {xylose }}+c_{\text {xylitol }}}\left[\ln (0.9993)-\frac{0.1603}{T}+0.00041126 \ln \left(P_{H_{2}}\right)\right] \\
C_{H_{2}}= & C_{\text {tot }} \times x_{H_{2}}
\end{aligned}
$$

Due to very tiny amount of samples withdrawn from reaction solution for HPLC analysis, we assumed that a constant reaction liquid volume always be maintained. Thus the ideal batch reactor model was used where the mass balance can be written as follows:

$\frac{d c_{i}}{d t}=\rho_{B} r_{i}$

where catalyst bulk density $\rho_{\mathrm{B}}=\mathrm{m}_{\text {cat }} / \mathrm{V}_{\text {reactor }}$.

The influence of heat of adsorption was included in the parameter estimation but a low value that was not well identified $(0.743 \mathrm{~kJ} / \mathrm{mol}$, error $1200 \%)$ was obtained. Therefore the heat of adsorption was considered as zero in the final version of the model. The temperature dependence of the rate constant can be described with the Arrhenius equation:

$k=k_{0} e^{-\frac{E_{a}}{R}\left(\frac{1}{T}-\frac{1}{T}\right)}$

The system of ordinary differential equations was solved numerically performed with the backward difference method as a subtask for the parameter estimator. The parameter estimation was done with Simplex and Levenberg-Marquardt methods. All numerical tools are in the used software Modest ${ }^{\circledR}$ (Haario, 1994). On the basis of the mentioned model, the kinetic parameters for the studied reaction system were estimated including the frequency factor $\mathrm{k}_{0}$, activation energy $\mathrm{E}_{\mathrm{a}}$ and adsorption coefficients $\mathrm{K}_{\mathrm{xylose}}$ and $\mathrm{K}_{\mathrm{H} 2}$. An excellent agreement $(99.6 \%)$ between the model fit and the experimental data was obtained (Table 3). The fit of the model to experimental data which also can be seen in Figure 12 showed that the proposed reaction kinetics model describes the experimental data very well for the studied pressure and temperature range. As can be seen (Table 4), the activation energy $\left(E_{A}\right)$ for xylose hydrogenation was estimated to about $53.1 \mathrm{~kJ} / \mathrm{mol}$, a value equal to the reported value for a Ra-Ni catalyst [7] and close with the reported value for a ruthenium based catalyst [27]. Consequently, this demonstrates that the $\mathrm{Ru} /$ CF catalyst (with SRBR) possesses high catalytic activity toward the hydrogenation of D-xylose to D-xylitol.

\section{Conclusions}

Catalytic hydrogenation of D-xylose to D-xylitol over Ru supported on carbon foam catalyst and the use of the SRBR concept was studied. The use of SRBR and Ru/CF (Ru, 3 wt $\%$ on carbon foam) catalyst gave rise to comparable reaction rates, conversions and selectivity towards D-xylitol as the commercial reference catalyst (Ru/AC) in slurry operations. Moreover, considering the ease of catalyst recovery and product handling, the new Ru/CF-SRBR offers an attractive alternative to classical slurry operations. Nevertheless, fouling and Ru agglomeration were the main causes of slow deactivation. Further, the influence of temperature and pressure as well as the stirring speed on Dxylose conversion was studied. A competitive kinetics model in respect to hydrogen and xylose has been proposed that can describe the experimental data very well. Thus the model may be used to predict the behavior of the new $\mathrm{Ru} /$ CF-SRBR for scale-up purposes.

Acknowledgments SpinChem $\mathrm{AB}$ is thanked for providing the polymeric precursor materials and the SpinChem $\left.{ }^{(}\right)$rotating bed reactor. The Artificial Leaf, Bio4Energy programme \& the Kempe Foundations are acknowledged for funding. This work is also a part of the "Artificial Leaf" project activities funded by the Knut \& Alice 
Wallenberg foundation as well as the Johan Gadolin Process Chemistry Centre at Åbo Akademi University.

\section{References}

1. Holladay J, Bozell J, White J, Johnson D (2007) Top value-added chemicals from biomass. DOE Report PNNL 16983

2. Massoth D, Massoth G, Massoth IR, Laflamme L, Shi W, Hu C, Gu F (2006) The effect of xylitol on Streptococcus mutans in children. J Calif Dent Assoc 34(3):231-234

3. Takahashi Y, Takeda C, Seto I, Kawano G, Machida Y (2007) Formulation and evaluation of lactoferrin bioadhesive tablets. Int J Pharm 343(1):220-227

4. Sokmen A, Gunes G (2006) Influence of some bulk sweeteners on rheological properties of chocolate. LWT Food Sci Technol 39(10): 1053-1058

5. Tathod AP, Dhepe PL (2014) Towards efficient synthesis of sugar alcohols from mono- and poly-saccharides: role of metals, supports \& promoters. Green Chem 16(12):4944-4954

6. Research and Market (2014) Xylitol—a global market overview. http://www.researchandmarkets.com/reports/2846975/xylitol-aglobal-market-overview. Accessed 24 Sept 2015

7. Mikkola J-P, Vainio H, Salmi T, Sjöholm R, Ollonqvist T, Väyrynen J (2000) Deactivation kinetics of Mo-supported Raney Ni catalyst in the hydrogenation of xylose to xylitol. Appl Catal A 196(1):143-155

8. Yadav M, Mishra DK, Hwang J-S (2012) Catalytic hydrogenation of xylose to xylitol using ruthenium catalyst on $\mathrm{NiO}$ modified TiO 2 support. Appl Catal A 425:110-116

9. Gallezot P, Nicolaus N, Fleche G, Fuertes P, Perrard A (1998) Glucose hydrogenation on ruthenium catalysts in a trickle-bed reactor. J Catal 180(1):51-55

10. Hernández-Mejía C, Raja E, Olivos-Suarez A, Gascon J, Greer HF, Zhou W, Rothenberg G, Shiju RN (2015) Ru/TiO2-catalysed hydrogenation of xylose: the role of crystal structure of the support. Catalysis Science \& Technology 6(2):577-582

11. Mishra DK, Dabbawala AA, Park JJ, Jhung SH, Hwang J-S (2014) Selective hydrogenation of D-glucose to d-sorbitol over HY zeolite supported ruthenium nanoparticles catalysts. Catal Today 232:99-107

12. Luo C, Wang S, Liu H (2007) Cellulose conversion into polyols catalyzed by reversibly formed acids and supported ruthenium clusters in hot water. Angew Chem Int Ed 46(40):7636-7639

13. Pham TN, Samikannu A, Kukkola J, Rautio A-R, Pitkänen O, Dombovari A, Lorite GS, Sipola T, Toth G, Mohl M (2014) Industrially benign super-compressible piezoresistive carbon foams with predefined wetting properties: from environmental to electrical applications. Sci Rep 4:6933. doi:10.1038/srep06933

14. Coker AK (2001) Modeling of chemical kinetics and reactor design, vol 1. Gulf Professional Publishing, Houston

15. Eta V, Anugwom I, Virtanen P, Mäki-Arvela P, Mikkola J-P (2014) Enhanced mass transfer upon switchable ionic liquid mediated wood fractionation. Ind Crops Prod 55:109-115

16. Mallin H, Muschiol J, Byström E, Bornscheuer UT (2013) Efficient biocatalysis with immobilized enzymes or encapsulated whole cell microorganism by using the SpinChem reactor system. ChemCatChem 5(12):3529-3532

17. Chan HYH, Takoudis CG, Weaver MJ (1997) High-pressure oxidation of ruthenium as probed by surface-enhanced Raman and X-ray photoelectron spectroscopies. J Catal 172(2):336-345

18. Mun C, Ehrhardt J, Lambert J, Madic C (2007) XPS investigations of ruthenium deposited onto representative inner surfaces of nuclear reactor containment buildings. Appl Surf Sci 253(18): $7613-7621$

19. Kinoshita K, Bett JAS, Stonehart P (1975) Effects of gas-and liquid-phase environments on the sintering behavior of platinum catalysts. In: Kuczynski GC (ed) Sintering and catalysis. Springer, Boston, pp 117-132

20. Hassan SA (1974) Kinetics of sintering of unsupported platinum catalyst in nitrogen, oxygen and hydrogen atmospheres. J Appl Chem Biotechnol 24(9):497-503

21. Guisnet M, Magnoux P (2001) Organic chemistry of coke formation. Appl Catal A 212(1):83-96

22. Salmi T, Murzin DY, Mikkola J-P, Wärnå J, Mäki-Arvela $P$, Toukoniitty E, Toppinen S (2004) Advanced kinetic concepts and experimental methods for catalytic three-phase processes. Ind Eng Chem Res 43(16):4540-4550

23. Sifontes Herrera VA, Oladele O, Kordás K, Eränen K, Mikkola JP, Murzin DY, Salmi T (2011) Sugar hydrogenation over a Ru/C catalyst. J Chem Technol Biotechnol 86(5):658-668

24. Wisniak J, Hershkowitz M, Stein S (1974) Hydrogenation of xylose over platinum group catalysts. Ind Eng Chem Prod Res Dev 13(4):232-236

25. de Beeck BO, Dusselier M, Geboers J, Holsbeek J, Morré E, Oswald S, Giebeler L, Sels BF (2015) Direct catalytic conversion of cellulose to liquid straight-chain alkanes. Energy Environ Sci 8:230

26. Mikkola JP, Salmi T, Sjöholm R (1999) Modelling of kinetics and mass transfer in the hydrogenation of xylose over Raney nickel catalyst. J Chem Technol Biotechnol 74(7):655-662

27. Mishra DK, Dabbawala AA, Hwang JS (2013) Ruthenium nanoparticles supported on zeolite $\mathrm{Y}$ as an efficient catalyst for selective hydrogenation of xylose to xylitol. J Mol Catal A 376:63-70 